\title{
Response of Hepatitis B Vaccine in Children with Celiac Disease - An Experience at Ayub Teaching Hospital, Abbottabad Pakistan
}

\author{
Bibi Aliaa ${ }^{1}$, Syed Sajid Hussain Shah ${ }^{2}$ \\ ${ }^{1}$ Assistant Professor, Department of Pediatrics, Lady Reading Hospital Peshawar, Khyber Pakhtunkhwa, Pakistan \\ ${ }^{2}$ Assistant Professor, Department of Pediatrics, Ayub Medical College Abbottabad, Khyber Pakhtunkhwa, Pakistan
}

\begin{abstract}
Background: Celiac Disease (CD), characterized by chronic small intestinal inflammation, is an immune-mediated disorder, with a strong family history and association with DQ2 HLA haplotype. It has been postulated that children with $C D$ show less response to hepatitis $B$ vaccine due to overexpression of HLA-DQ2 haplotype. This study was done to determine the response of hepatitis $B$ vaccine in children with $C D$ in our tertiary care setting in the Hazara region of eastern Khyber Pakhtunkhwa, Pakistan.

Material and Methods: This cross-sectional study was conducted in the Pediatrics outpatient department (OPD) of Ayub Teaching Hospital, Abbottabad Pakistan from April 2018 till March 2020. Children with CD ( $n=38$ ) aged 1-14 years with completed HBV vaccination, anti-tissue transglutaminase IgA antibody (tTG-IgA) >150 IU/ml and/or typical histological findings of $C D$ on small-bowel biopsy, were included in the study. Hepatitis B surface antibody ( $\mathrm{HbsAb}$ ) titer of $\geq 10$ $\mathrm{mIU} / \mathrm{ml}$ was taken as antibody positive, while $\mathrm{HbsAb}$ levels $<10 \mathrm{mlU} / \mathrm{ml}$ were considered as vaccine non-responsive. Data was analyzed using SPSS version 20.0. Chi square test was applied for comparison with $P$-value $<.05$ taken as significant.

Results: Out of 38 diagnosed cases of CD, 15 (39.5\%) were males and 23 (60.5\%) were females. Mean age of children was $8.32 \pm 3.26$ years with an age range of 3-14 years. HbsAb levels ranged from 0.10 to $62.7 \mathrm{mIU} / \mathrm{ml}$ with a mean of $11.2+17.42 \mathrm{mIU} / \mathrm{ml}$. HbsAb levels were less than $10.0 \mathrm{IU} / \mathrm{ml}$ in $73.7 \%$ of children with CD. Small intestinal biopsy was performed in 11 (28.9\%) patients. There was a significant relationship between anti tTG-IgA levels and histopathology findings with $P$-value of .001.

Conclusions: In children having celiac disease, there was low rate of protective antibody response to hepatitis $B$ vaccine. Key words: Antibody response, Celiac disease, Hepatitis B vaccine, HbsAb levels.

Authors' Contribution:
1-2 Conception; Literature research;
manuscript design and drafting; Critical
analysis and manuscript review; Data
analysis; Manuscript Editing.

Article info:

Received: July 15, 2020

Accepted: June 4, 2021
\end{abstract}

Cite this article. Aliaa B, Shah SSH. Response of Hepatitis B Vaccine in Children with Celiac Disease - An Experience at Ayub Teaching Hospital, Abbottabad Pakistan. J Islamabad Med Dental Coll. 2021; 10(2): 95-100. Doi: 10.35787/jimdc.v10i2.565

\author{
Correspondence: \\ Syed Sajid Hussain Shah \\ Email: syed_sajid20@yahoo.com
}

Funding Source: Nil

Conflict of Interest: Nil 


\section{Introduction}

Celiac disease (CD) is an immune mediated-disorder with a strong genetic predisposition. It is characterized by chronic small intestinal inflammation induced by ingestion of gluten moiety in the diet. Worldwide the estimated prevalence of CD in children is about $1 \% .{ }^{1}$ In 2010, 2.2 million children under five years of age were diagnosed with celiac disease. It has an immunological basis as evidenced by a strong family history and association with the DQ2 HLA haplotype. Individuals lacking the DQ2 haplotype are generally positive for DQ8..$^{2-4}$

Hepatitis B virus (HBV) vaccine was introduced in the early 1980s for use in individuals at high risk for acquiring HBV infection. In Pakistan, it is currently administered to all infants as part of the EPI (Expanded Programme on Immunization) program. It is also administered to previously unvaccinated adults at high-risk, in an attempt to achieve universal protection against HBV infection. A course of three doses of hepatitis $B$ vaccine can be administered in a variety of schedules: such as at birth, 1- and 6months schedule, the 6-, 10- and 14-weeks doses and the 2-, 4- and 6-months schedule. All schedules induce protective levels of antibody to hepatitis $B$ surface antigen ( $\mathrm{HbsAg}$ ) in majority of healthy infants and children. ${ }^{5}$ About $90 \%$ of adult population respond to HBV vaccination. ${ }^{6}$ Non-responders are often found to carry specific human leukocyte antigen (HLA) haplotype, including DR7, DR3, and DQ2. ${ }^{7}$

Since the HLA-DQ2 haplotype is over-represented in celiac population, it seems reasonable to hypothesize that patients with Celiac Disease are less able to respond to $\mathrm{HBV}$ vaccine than the general population, whose frequency of HLA haplotype B8, $D R 3$, and DQ2 are much lower. It has been postulated that this genetic profile may play a crucial role in predisposing celiac patients to a lower grade of immunization to hepatitis $B$ vaccine. ${ }^{8}$

$C D$ is not an uncommon disease. There is scarcity of data regarding exact prevalence of $C D$ and response of children with $C D$ to hepatitis $B$ vaccination. ${ }^{9}$ The problem of chronic HBV infection and its associated complications like liver carcinoma remains a major public health problem. Children with CD who are non-responsive to HBV vaccination could be considered as a large reservoir of HBV-susceptible individuals who will persist as healthy carriers, leading to spread of the disease in healthy subjects. This study was therefore carried out to determine the response of hepatitis $B$ vaccine in children with $C D$ presenting in the outpatient department (OPD) of Pediatrics at Ayub Teaching Hospital, Abbottabad, Pakistan.

\section{Material and Methods}

This cross-sectional study was conducted in the Pediatrics OPD of Ayub Teaching Hospital, Abbottabad in Hazara Division, KPK, Pakistan from April, 2018 till March, 2020. Approval was sought from the Ethics Committee of Ayub Medical Institutions, Abbottabad Pakistan. Informed consent was taken from parents prior to the conduct of research. Sample size $(n=27)$ was calculated with OpenEpi sample size calculator for cross-sectional studies, taking prevalence of CD in children as $1 \%^{1}$ and confidence interval of $95 \%$. A total of 38 patients were included in the study using purposive sampling technique. The study population included both new and old cases of celiac disease diagnosed during the study period. Children aged 1 to 14 years, diagnosed with $C D$ on the basis of a thorough history were included. Laboratory diagnosis of CD was done on standard clinical criteria including abnormal serological marker, anti-tissue transglutaminase IgA 
antibody (tTG-IgA) >150 IU/ml and/or small-bowel biopsy histological findings such as villous atrophy with crypt hyperplasia and increased intraepithelial lymphocytes. Biopsy was not done in patients with anti tTG-IgA level $>150 \mathrm{IU} / \mathrm{ml}$. Other inclusion criterion was that patient must have completed three full doses of recombinant HBV vaccination as evidenced by EPI/vaccination card. Children with chronic hepatitis B infection, immunodeficiency or on immunosuppressant drugs and chronic diarrhea due to other causes were excluded.

Clinical data was compiled for each subject from a review of previous medical and vaccination records. Age, sex, immunization status especially HBV vaccination (including timing of immunizations), age of diagnosis for $C D$, results of celiac panel if it was done within 2 months before the antibody testing (as a reflection of adherence to gluten-free diet in CD group), medication (current and past), coexisting medical condition and family history were recorded.

Patients diagnosed with $C D$ were tested for hepatitis $B$ surface antibody (HbsAb). Samples with antibody titers of $\geq 10 \mathrm{mIU} / \mathrm{ml}$ were taken as positive. $\mathrm{HbsAb}$ levels less than $10 \mathrm{mIU} / \mathrm{ml}$ were considered a vaccine non-responsive. These children were given one extra shot of HBV vaccine. Data was entered on specific proforma which included chronological age, age at diagnosis, sex, weight, height, presenting complaint, co-morbid condition (diabetes mellitus, hypothyroidism, epilepsy, dermatitis herpetiformis) anti tTG-IgA level, histopathology (if biopsy done), HbsAb level along with both mother and father education. Data was analyzed using SPSS version 20.0. Chi square test was used for comparison of different variables with $P$-value less than .05 considered as statistically significant.

\section{Results}

Out of 38 diagnosed cases of CD, 39.5\% ( $n=15)$ were male and $60.5 \%(n=23)$ were female. Mean age of children was $8.32 \pm 3.26$ years with an age range of 3 14 years. Mean values of age at diagnosis, height, weight, anti tTG-IgA and HbsAb levels are given in table I. The most common presenting complaint for which patient visited the OPD was chronic diarrhea ( $n=21 ; 55.3 \%)$ followed by pallor ( $n=10 ; 26.3 \%)$ (Table II). Regarding age at diagnosis, almost half of the children $(n=20 ; 52.6 \%)$ were diagnosed in $>5$ years to 10 years age group followed by $<5$ years $(n=11 ; 28.9 \%)$ and $>10$ years age group $(n=7 ; 18.4 \%)$.

\begin{tabular}{|l|c|c|c|}
\hline \multicolumn{4}{|c}{ Table I: Baseline characteristics of children with celiac } \\
disease \\
\hline Characteristics & Min & Max & Mean \pm SD \\
\hline Age (years) & 3.00 & 14.00 & $8.32 \pm 3.26$ \\
\hline Weight (kg) & 6.90 & 42.00 & $19.18 \pm 8.15$ \\
\hline Height (cm) & 70.00 & 157.90 & $113.46 \pm 21.52$ \\
\hline $\begin{array}{l}\text { Age at diagnosis } \\
\text { (years) }\end{array}$ & 2.00 & 14.00 & $7.51 \pm 3.57$ \\
\hline $\begin{array}{l}\text { Anti tTG-IgA } \\
(\text { IU/ml) }\end{array}$ & 11.90 & 800.00 & $242.02 \pm 173.09$ \\
\hline $\begin{array}{l}\text { HbsAb level } \\
(\mathrm{mlU} / \mathrm{ml})\end{array}$ & 0.10 & 62.71 & $11.21 \pm 17.42$ \\
\hline
\end{tabular}

Most of the mothers (71.1\%) were educated up to tenth grade (Secondary school/High school level) while most of the fathers (71.1\%) had higher level of education (Eleventh grade/Intermediate or higher).

Most of the children with $C D(n=32 ; 84 \%)$ had higher levels of anti tTGA-IgA than the cut-off value of 150 $\mathrm{IU} / \mathrm{ml}$. Small bowel biopsy was done in all patients with anti tTG-IgA levels $<150 \mathrm{IU} / \mathrm{ml}$, except one patient. In majority of patients with anti tTG-IgA levels $>150 \mathrm{IU} / \mathrm{ml}$, small bowel biopsy was not done. Histopathology of small bowel showed increased epithelial lymphocytes along with villous atrophy. 


\begin{tabular}{|c|c|}
\hline \multicolumn{2}{|c|}{$\begin{array}{c}\text { Table II: Presenting complaints of patients with celiac } \\
\text { disease }\end{array}$} \\
\hline Complaints & $\begin{array}{l}\text { Frequency } \\
\mathrm{n}(\%)\end{array}$ \\
\hline Pallor & $10(26.3)$ \\
\hline Failure to thrive & $1(2.6)$ \\
\hline Diarrhea & $21(55.3)$ \\
\hline Constipation & $3(7.9)$ \\
\hline Abdominal distension & $1(2.6)$ \\
\hline Short stature & $2(5.3)$ \\
\hline Total & $38(100)$ \\
\hline
\end{tabular}

There was significant relationship between anti tTGIgA levels and histopathology findings $(P=.001)$. $\mathrm{HbsAb}$ levels were less than $10.0 \mathrm{IU} / \mathrm{ml}$ in majority of patients, with $28(73.7 \%)$ patients having antibody less than protective levels and only 10 (26.3\%) patients having levels in the protective range. In children with anti tTG-IgA level more than 150 $\mathrm{IU} / \mathrm{ml}$, majority of patients $(71.87 \%)$ were having anti HbsAb levels less than $10 \mathrm{mIU} / \mathrm{ml}(P=.559)$.

\section{Discussion}

In this study we report lower levels of HBsAb $(<10.0$ $\mathrm{IU} / \mathrm{ml}$ ) in $73.7 \%$ of $\mathrm{CD}$ children $(\mathrm{n}=38)$ with a mean age of 8 years in our tertiary care set-up at Abbottabad, Pakistan. Some of the affected children can present with involvement of endocrine, neural, liver, heart, and skin as atypical presentation of CD. Autoimmune diseases are more prevalent in children with $C D$ as compared to normal healthy children. ${ }^{10}$ Hepatitis $B$ viral infection in very much prevalent in our part of the country and children with less levels of protective $\mathrm{HbsAb}$ are prone to infection despite completing the series of HBV vaccination. Inclusion of HBV vaccine in national immunization program has led to a decrease in chronic HBV carriers and liver cancer associated with it. $^{11,12}$

Sparks et al. ${ }^{13}$ studied children with CD recorded in the institutional registry and developed a Celiac Care Index. The common presentation was iron deficiency (41\%) in their study. We reported history of progressive pallor in $26.3 \%$ of the patients. Non immunity to HBV in their study was comparable to our findings (70\% versus $73.7 \%$ ). Another study by Walkiewicz-Jedrzejczak et al. ${ }^{14}$ included children with CD who had completed primary HBV vaccination. More than half of the children (58\%) in this study did not have protective antibody levels in response to HBV vaccine. Ertekin et al. ${ }^{15}$ also compared response to standard HBV vaccine in $C D$ and healthy children. Male and female distribution of celiac disease was comparable to our study. HBV vaccine non-responders were $38.5 \%$ as compared to $73.7 \%$ in our study. Snyder et al. ${ }^{16}$ in their expertinformed recommendations for management of $C D$ in children endorsed routine screening for $\mathrm{HB}$ immunization status. Most of the studies have shown that $30-70 \%$ of children with CD are nonresponsive to HBV vaccine. ${ }^{16}$ Zifman et al. ${ }^{17}$ retrospectively evaluated $C D$ children for the effect of gluten free diet on HbsAb response. They found no relation of gluten free diet on pre- and post $\mathrm{HbsAb}$ levels. Urganci and Kalyoncu ${ }^{18}$ studied hepatitis $A$ and hepatitis $B$ vaccine response in children with $\mathrm{CD}$. Children who got HBV vaccine, the overall response rate in protective range was $70 \%$. This is in sharp contrast to our reported figure of $26.3 \%$. Though the exact reason for this difference in response is not known, genetic factors may be responsible and should be explored. In a study by Filippelli et al. ${ }^{19}$ patients were grouped according to age. Majority (48.9\%) of their patients were in age category of 0 to 5.5 years at diagnosis while in our study majority (52.6\%) of patients were between 5.1 to 10 years of age. This may be due to lack of education of parents specifically mothers, as most of them were educated up to high school level (10th grade) or even less. In our setup most of the children are brought to hospital by mothers. In Filippelli et al. ${ }^{19}$ study the overall response rate of HBV vaccine in all three age groups was $69.37 \%$, while in our study group it was only $26.3 \%$. In study by Leonardi et al. ${ }^{20} 50 \%$ of patients did not show response to 
HBV vaccine. In our study, 73.7\% patients were not having $\mathrm{HbsAb}$ in protective range. This difference can also be attributed to genetic differences between the two populations. Rousseff et al. ${ }^{21}$ included 133 children with celiac disease in their study with $35 \%$ affected males and $55 \%$ were nonresponsive to HBV vaccine. Rousseff et al. gave booster shot of HBV and the non-response rate reduced from $55 \%$ to $23 \%$.

Anania et al. ${ }^{22}$ recommended practical guidelines for vaccination of children with $C D$ as $H B V$ vaccine response in children with $C D$ is less and it may be related to HLA or gluten exposure at the time of vaccination. Vitaliti and colleagues ${ }^{23}$ in their mini review highlighted the possible factors in nonresponsiveness of $C D$ children to $H B V$ vaccine and emphasized for the alternate schedule of HBV vaccine. Heshin-Bekenstein et al. ${ }^{24}$ compared pre-S vaccine with standard $\mathrm{HBV}$ vaccine in children who were known cases of $C D$. Pre-S vaccine is recombinant hepatitis $B$ vaccine, containing major $S$ protein and minor pre-S1 and pre-S2 proteins of HBV coat. These children completed their primary immunization course and their $\mathrm{HbsAb}$ were not in the protective range. The response to standard HBV vaccine was $87 \%$ after one month as compared to pre-S vaccine, whose response rate was $98 \%$. In our study, we gave one extra shot of standard HBV vaccine.

A major limitation of our study was checking HBsAb level only once due to high cost of the test. So, it is not clear if our population is responsive to the extra shot of hepatitis B vaccine. Another limitation in this study was that we only included children with $C D$ and no comparison was done with healthy population. Therefore, we cannot comment on the actual difference of response between diseased and non-diseased children. Due to rare availability and high cost, HLA DQ2 test was not done. This study gave insight in to the prevalence of nonresponsiveness to hepatitis $B$ vaccine in children with $C D$ who are prone to be infected with hepatitis $B$ virus in our population.

\section{Conclusion}

Children with celiac disease are less responsive to hepatitis $B$ vaccine. These children should be tested for HbsAb levels, apart from monitoring adherence to gluten free diet and surveillance for other autoimmune diseases.

\section{References}

1. Hashmi MA, Hussain T, Masood N, Younas M, Ashghar RM, Shafi MS. Accuracy of Anti-Tissue Transglutaminase IgA Antibody in the diagnosis of paediatric celiac disease. J Coll Physicians Surg Pak. 2016; 26: 263-6.

2. Bingham SM, Bates MD. Pediatric celiac disease: A review for non-gastroenterologists. Curr Probl Pediatr Adolesc Health Care. 2020; 50(5): 1-4. Doi: 10.1016/j.cppeds.2020.100786.

3. Özgenel ŞM, Temel T, Üsküdar Teke $H$, Yıldız $P$, Korkmaz H, Özakyol A. HLA-DQ2/DQ8 frequency in adult patients with celiac disease, their first-degree relatives, and normal population in Turkey. Turk J Gastroenterol. 2019; 30(4): 321-5. Doi: 10.5152/tjg.2019.18255.

4. Cabrera CM, Godoy LS, López VMN. Is the double gene dose of DQ2.5 or DQ2.5/DQ2.2 an involved factor in the clinical features of celiac disease? Scand J Gastroenterol. 2019; 54(8): 960-4. Doi: 10.1080/00365521.2019.1647283

5. Posuwan N, Wanlapakorn, Vongpunsawad S, Sintusek P, Leuridan E, Damme PV, et al. Comparison of hepatitis $B$ surface antibody levels induced by the pentavalent DTwP-HB-Hib versus the hexavalent DTaP-HB-Hib-IPV vaccine, administered to infants at $2,4,6$, and 18 months of age, following monovalent hepatitis B vaccination at birth. Vaccine. 2020; 38(7): 1643-51. Doi: 10.1016/j.vaccine.2019.12.065.

6. 6.Kayar Y, Dertli R. Factors affecting hepatitis B immunization in celiac disease. Ann Med Res. 2019; 26(8): 1478-83. Doi: 10.5455/annalsmedres.2019. 05.296.

7. Passanisi S, Dipasquale V, Romano C. Vaccinations and Immune Response in Celiac Disease. Vaccines. 2020; 8(2): 278. Doi: 10.3390/vaccines8020278.

8. Noh KW, Poland GA, Murray JA. Hepatitis B vaccine nonresponse and celiac disease. Am J Gastroenterol. 
2003; 98: 2289-92. Doi: 10.1111/j.1572-0241.2003. 07701.x.

9. Rashid $M$, Rashid H.J Pak Med Assoc 2019;69(12):1883-8.doi: 10.5455/JPMA.286805.

10. Ahishali E, Boztas G, Akyuz F, Ibrisim D, Poturoglu S, Pinarbasi $B$, et al. Response to hepatitis $B$ vaccination in patients with celiac disease. Dig Dis Sci. 2008; 53(8): 2156-9. Doi: 10.1007/s10620-007-0128-3.

11. Liang X, Bi S, Yang W, Wang L, Cui G, Cui F, et al. Evaluation of the impact of hepatitis $B$ vaccination among children born during 1992-2005 in China. J Infect Dis. 2009; 200: 39-47. Doi: 10.1086/599332.

12. McMahon BJ, Bulkow LR, Singleton RJ, Williams J, Snowball M, Homan $C$, et al. Elimination of hepatocellular carcinoma and acute hepatitis $B$ in children 25 years after a hepatitis B newborn and catch-up immunization program. Hepatology. 2011; 54: 801-7. Doi: 10.1002/hep.24442.

13. Sparks B, Salman S, Shull M, Trout A, Kiel A, Hill I, et al. A Celiac Care Index Improves Care of Pediatric Patients Newly Diagnosed with Celiac Disease. J Pediatr. 2020; 216: 32-6. Doi: 10.1016/j.jpeds. 2019.09.071.

14. Walkiewicz-Jedrzejczak D, Egberg M,Nelson C, Eickoff J. Evaluation of the response to vaccination with hepatitis $B$ vaccine in pediatric patients diagnosed with celiac disease. SAGE Open Med. 2014; 2: 1-5. Doi: $10.1177 / 2050312114563346$.

15. Ertekin V, Tosun MS, Selimoglu MA. Is there need for a New Hepatitıs B Vaccine Schedule for Children with Celiac Disease? Hepat Mon. 2011; 11(8): 634-7. Doi: 10.5812/kowsar.1735143X.715.

16. Snyder J, Butzner JD, De Felice AR, Fasano A, Guandalini S, Liu E, et al. Evidence-Informed Expert Recommendations for the Management of Celiac Disease in Children. Pediatrics. 2016; 138(3): e20153147.1-17. Doi: 10.1542/peds.2015-3147.

17. Zifman E, Zevit N, Heshin-Bekenstein M, Turner D, Shamir R, Silbermintz A. Effect of a Gluten Free Diet on Hepatitis B Surface Antibody Concentration in Previously Immunized Pediatric Celiac Patients. Pediatr Gastroenterol Hepatol Nutr. 2020; 23(2): 132-6. Doi: 10.5223/pghn.2020.23.2.132.

18. Urganci N, Kalyoncu D. Response to Hepatitis A and B Vaccination in Pediatric Patients with Celiac Disease. J Pediatr Gastroenterol Nutr. 2013; 56: 408-11. Doi: 10.1097/MPG.0b013e31827af200.

19. Filippelli M, Garozzo MT, Capizzi A, Spina M, Manti S, TardinoL, Salpietro C, Leonardi S. Immune response to hepatitis B virus vaccine in celiac subjects at diagnosis. World J Hepatol. 2016; 8(26): 1105-9. Doi: 10.4254/wjh.v8.i26.1105.

20. Leonardi S, Spina M, Spicuzza L, Rotolo N, Rosa ML. Hepatitis B vaccination failure in celiac disease: Is there a need to reassess current immunization strategies? Vaccine. 2009; 27(43): 6030-3. Doi: 10.1016/j.vaccine.2009.07.099.

21. Rousseff T, Claeys T, Vande Vijver E, Moes N, Vande Velde $S$, Schelstraete $P$, et al. Hepatitis $B$ virus vaccination and revaccination response in children diagnosed with coeliac disease: a multicenter prospective study. Acta Gastroenterol Belg. 2019; 82(1): 27-30.

22. Anania C, Olivero F, Spagnolo A, Chiesa C, Pacifico L. Immune response to vaccines in children with celiac disease. World J Gastroenterol. 2017; 23(18): 320513. Doi: $10.3748 /$ wjg.v23.i18.3205.

23. Vitaliti G, Praticò AD, Cimino C, Di Dio G, Lionetti E, La Rosa M, Leonardi S. Hepatitis B vaccine in celiac disease: Yesterday, today and tomorrow. World J Gastroenterol. 2013; 19(6): 838-45. Doi: 10.3748/wjg.v19.i6.838.

24. Heshin-Bekenstein M, Turner D, Shamir R, Bar-Meir M, Dagan R, Zevit $N$, et al. Hepatitis B Virus Revaccination with Standard versus Pre-S Vaccine in Previously Immunized Patients with Celiac Disease. J Pediatr Gastroenterol Nutr. 2015; 61: 400-3. Doi: 10.1097/MPG.0000000000000856. 